\title{
Large Isolated Internal Iliac Artery Aneurysm
}

\author{
Georgios Vourliotakis ${ }^{1}$, Ioannis Kantounakis ${ }^{2}$, Sotirios Plakas ${ }^{3}$ and Vasileios D. Tzilalis ${ }^{1}$
}

Key words: internal iliac artery aneurysm, iliac artery embolization, large iliac aneurysm

(Intern Med 54: 983-984, 2015)

(DOI: 10.2169/internalmedicine.54.3641)

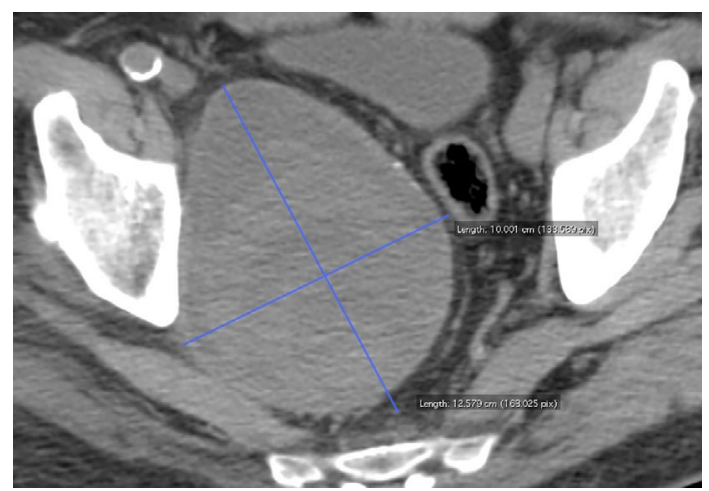

Picture 1.

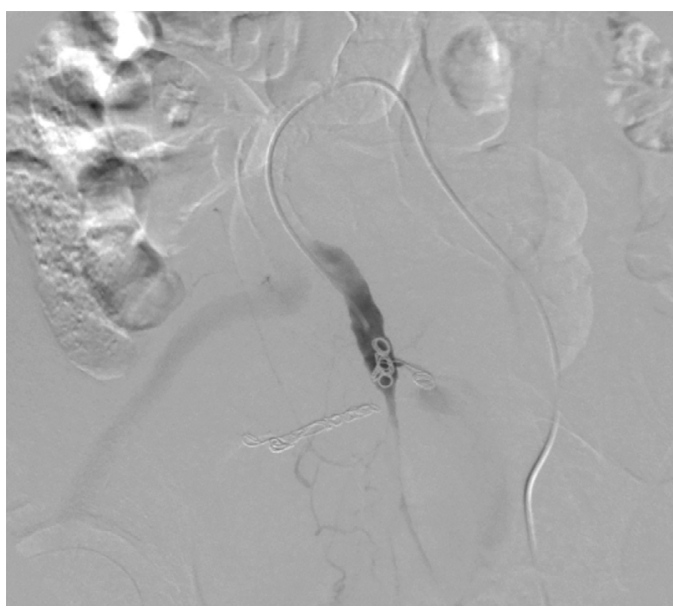

Picture 3.

We experienced a rare case of a large internal iliac artery aneurysm in a 74-year-old man. The patient's medical history included right leg claudication that had worsened over the previous two months and was initially attributed to a coexistent herniated lumbar disc.

Computed tomography angiography (CTA) revealed a

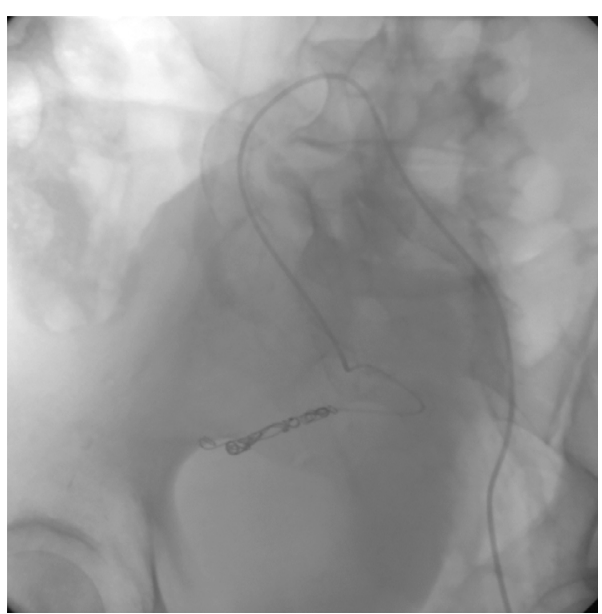

Picture 2.

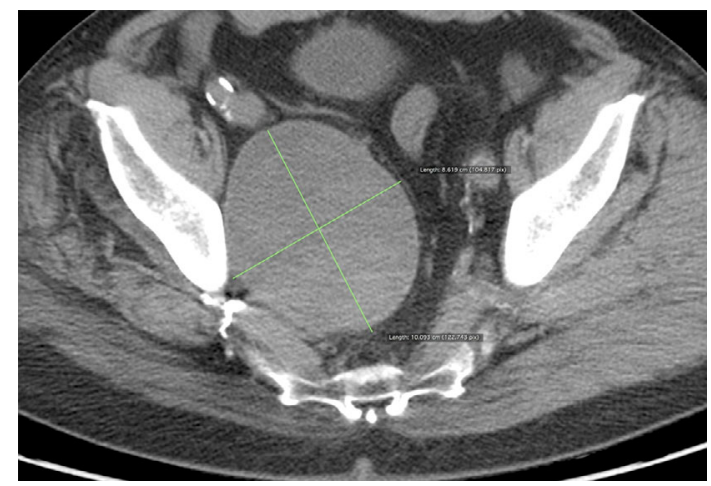

Picture 4. large right internal iliac artery aneurysm measuring $12.5 \times 10$ $\mathrm{cm}$ in size, without other iliac or aortic aneurysms (Picture 1).

The patient was managed with endovascular treatment. Complete selective embolization via the contralateral approach through the distal branches of the right internal iliac

${ }^{1}$ Department of Surgery (Division of Vascular Surgery), 401 General Military Hospital of Athens, Greece, ${ }^{2}$ Angiography Department, 401 General Military Hospital of Athens, Greece and ${ }^{3}$ Neurosurgery Department, 401 General Military Hospital of Athens, Greece

Received for publication July 16, 2014; Accepted for publication September 15, 2014

Correspondence to Dr. Georgios Vourliotakis, geovour@gmail.com 
artery (Picture 2) and proximal internal iliac artery (Picture 3) was performed with multiple coils $(1,2)$.

The patient showed a gradual improvement in symptoms without buttock claudication or sexual dysfunction.

On the annual follow-up, CTA revealed shrinkage of the aneurysm, with a diameter of $10 \mathrm{~cm}$ (Picture 4).

The authors state that they have no Conflict of Interest (COI).

\section{References}

1. Wilhelm BJ, Sakharpe A, Ibrahim G, Baccaro LM, Fisher J. The 100-year evolution of the isolated internal iliac artery aneurysm. Ann Vasc Surg 28: 1070-1077, 2014.

2. Muradi A, Yamaguchi M, Okada T, et al. Technical and outcome considerations of endovascular treatment for internal iliac artery aneurysms. Cardiovasc Intervent Radiol 37: 348-354, 2014.

(C) 2015 The Japanese Society of Internal Medicine http://www.naika.or.jp/imonline/index.html 